\title{
Estimation of the environmental effect of natural volatile organic compounds from Chamaecyparis obtusa and their effect on atopic dermatitis-like skin lesions in mice
}

\author{
HYUN YANG ${ }^{1}$, CHANGHWAN AHN $^{1}$, IN-GYU CHOI ${ }^{2}$, WON-SIL CHOI ${ }^{3}$, \\ MI-JIN PARK ${ }^{4}$, SUNG-SUK LEE $^{4}$, DON-HA CHOI ${ }^{4}$ and EUI-BAE JEUNG ${ }^{1}$ \\ ${ }^{1}$ Laboratory of Veterinary Biochemistry and Molecular Biology, College of Veterinary Medicine, \\ Chungbuk National University, Cheongju, Chungbuk 361-763; ${ }^{2}$ Department of Forest Sciences, \\ College of Agriculture and Life Sciences, Seoul National University; ${ }^{3}$ Chromatography Laboratory, \\ National Instrumentation Center for Environmental Management, Seoul National University, Seoul 151-921; \\ ${ }^{4}$ Department of Forest Products, Division of Wood Chemistry and Microbiology, \\ Korea Forest Research Institute, Seoul 130-712, Republic of Korea
}

Received April 29, 2014; Accepted February 5, 2015

DOI: $10.3892 / \mathrm{mmr} .2015 .3431$

\begin{abstract}
Aromatherapy has been suggested as an alternative therapeutic method for the treatment of atopic dermatitis (AD), eczema and other skin diseases. In the current study, the anti-atopic properties of the volatile organic compounds of Chamaecyparis obtusa (VOCCo) were examined to determine whether they are amenable for use as a pharmaceutical candidate. The alterations in histological features, serum IgE levels and mast cell infiltration following exposure to VOCCo were determined in a 2,4-dinitrochlorobenzene (DNCB)-induced AD-like mouse model. The results of these experiments demonstrated that VOCCo inhibited the development of AD-like skin lesions by reducing the serum IgE level and mast cell infiltration into the dermal and subcutaneous layers. This was supported by screening of immune cytokine mRNAs, including interleukin (IL)-1 $1 \beta$ and IL-6 from the skin of DNCB-treated mice. The expression of IL-1 $\beta$ and IL-6 in the skin lesions of mice was dose-dependently inhibited by treatment with VOCCo. Furthermore, treatment with VOCCo resulted in the recovery of histopathological features in AD-like skin lesions. These results suggest that VOCCo may have therapeutic and preventive effects for the development of AD.
\end{abstract}

Correspondence to: Professor Eui-Bae Jeung, Laboratory of Veterinary Biochemistry and Molecular Biology, College of Veterinary Medicine, Chungbuk National University, 52 Naesudongro, Cheongju, Chungbuk 361-763, Republic of Korea

E-mail: ebjeung@chungbuk.ac.kr

Key words: Chamaecyparis obtusa, atopic dermatitis, 2,4-dinitrochlorobenzene, volatile organic compounds of Chamaecyparis obtusa

\section{Introduction}

Atopic dermatitis (AD) has a complex etiology encompassing immunological responses, susceptibility genes, environmental triggers and compromised skin-barrier function (1). AD, also known as eczema, is a chronic inflammatory skin disease, which can occur in children and adults (2). AD is accompanied by symptoms of pruritus, erythema, edema and xerosis (3). The mechanisms underlying these skin diseases are also associated with genetic and environmental factors of AD pathogenesis (4). Immunoglobulin $(\mathrm{Ig}) \mathrm{E}$, which is important in the pathogenesis of allergy, is produced by B-lymphocytes following exposure of dendritic cells to a foreign antigen under the control of T-helper lymphocytes (5). An association between 70-85\% of human $\mathrm{AD}$ and $\mathrm{IgE}$ hyper-production has been demonstrated and the extent of IgE sensitization is directly associated with the severity of the disease (6). When two or more molecules of IgE bound to the surface of an immune cell are simultaneously linked to its specific allergen, the immune cell immediately releases preformed inflammatory mediators, including histamine, which induces the immediate effects or early phase of an allergic reaction (1). Following IgE release, immune cells also synthesize newly formed inflammatory molecules, including cytokines, such as interleukins (IL) $(1,7,8)$. The AD animal model, 2,4-dinitrochlorobenzene (DNCB)-induced contact hypersensitivity of the skin, is commonly used for investigating the pathogenesis of allergic contact dermatitis (9). DNCB, an allergen, can be internalized by local antigen presenting cells, including dermal dendritic cells and macrophages, processed and presented to $\mathrm{T}$ cells in the lymph nodes for activation (5), and cause AD like-symptoms, including eczema, erythema, scaling and hemorrhaging in skin lesions $(1,6,8,10,11)$.

Chamaecyparis obtusa (C. obtusa), a species of cypress, is a tropical tree native to the central part of Japan and the southern part of Korea. Essential oil extracted from C. obtusa contains several types of terpenes, including monoterpenes, sesquiterpenes and diterpenes. The crude extract of C. obtusa 
reduces allergic reactions in an AD mouse model and effectively suppresses the levels of serum IgE and proinflammatory cytokines, as well as mast cell appearance under the dermis and hypodermis (12). C. obtusa, regarded as the most representative medicinal plant, contains active terpene compounds, which may have pharmacological effects (13). Volatile organic compounds (VOC) have been found to demonstrate an association with asthma and immune responses (14-16). To the best of our knowledge, there are no studies indicating that exposure to the volatile organic compounds of C. obtusa (VOCCo) can reduce allergic symptoms and, in particular, specific $\operatorname{IgE}$ responses and immune cell infiltration. In addition, the underlying mechanisms of the hypo-allergic effects of VOCCo have not yet been elucidated. The aim of the current study was to investigate whether VOCCo exposure is able to improve the symptoms of $\mathrm{AD}$ and to determine whether it is amenable for use as a pharmaceutical candidate.

\section{Materials and methods}

Animals and induction of an AD mouse model. BALB/c mice (7 weeks old) were purchased from Koatech (Pyeongtaek, Republic of Korea) and were housed in polycarbonate cages with $C$. obtusa panel and corn cob bedding and acclimated in an environmentally controlled room (temperature, $23 \pm 2^{\circ} \mathrm{C}$; relative humidity, $50 \pm 10 \%$; frequent ventilation and a $12: 12$-h light-dark cycle). The animal experiments were approved by the Chungbuk National University Animal Care and Use Committee (Cheongju, Korea) and all procedures were performed in accordance with the Guide for the Care and Use of Laboratory Animals published by the National Institutes of Health (Bethesda, MD, USA). DNCB (Sigma-Aldrich, St. Louis, MO, USA) dissolved in acetone:olive oil $(4: 1)$ was used for the induction of dermatitis in BALB/c mice. Briefly, hair was removed from a $2 \times 4 \mathrm{~cm}$ region spanning from the neck to the pelvis and the dorsal skin was sensitized with $100 \mu \mathrm{l}$ of $2 \%$ DNCB for 2 days during the first week. Following the first sensitization, $100 \mu \mathrm{l}$ of $0.5 \%$ DNCB was applied three times a week to the dorsal skin for an additional 8 weeks. The VOCCo-untreated groups included the vehicle-treated (VE) group, DNCB treatment only group (DNCB) and the Clobetasol propionate ointment group $(\mathrm{DNCB}+\mathrm{CP})$. The VOCCo-treated groups included the DNCB+P1 group (C. obtusa panel, $\left.342 \mathrm{~cm}^{3}\right), \mathrm{DNCB}+\mathrm{P} 2$ group $\left(684 \mathrm{~cm}^{3}\right)$ and the DNCB+P3 group $\left(1,026 \mathrm{~cm}^{3}\right)$. No substances were applied to the skin surface on the final day of the experiment. The mice were then sacrificed by ether inhalation and the skin, lymph nodes and blood samples were collected for further analysis.

Level of serum IgE in an AD-like mouse model. Blood samples were collected directly from the inferior vena cava using a capillary tube at the end of the experiment. Serum was obtained by centrifugation at $3,000 \mathrm{x} \mathrm{g}$ for $10 \mathrm{~min}$ at $4^{\circ} \mathrm{C}$ and stored at $-70^{\circ} \mathrm{C}$ until use. Serum IgE levels were measured using a mouse IgE ELISA Ready-Set-Go kit (eBiosciences, San Diego, CA, USA) according to the manufacturer's instructions.

Histopathological alterations in an AD-like mouse model. Dermis tissue was fixed by inflating the tissue with $10 \%$ formalin. The tissues were then embedded in paraffin, cut into sections $(5 \mu \mathrm{m})$ and stained with hematoxylin and eosin (H\&E). All tissue samples were examined and images were captured and scored in a blinded manner under a light microscope (BX51; Olympus, Tokyo, Japan). Images were captured on an Olympus DP controller and manager under a microscope at (BX51; Olympus) x100 magnification. For examination of the distribution of mast cells beneath the dermis and hypodermis, the prepared tissues were stained with toluidine blue and images were captured on an Olympus DP controller and manager under a microscope (BX51; Olympus) at x400 magnification. The number of mast cells in a $1 \mathrm{~mm}^{2}$ area was counted under a microscope at $\times 400$ magnification.

RNA extraction and quantitative polymerase chain reaction $(P C R)$. Total RNA was extracted from mouse skin using TRIzol reagent (Invitrogen Life Technologies, Carlsbad, CA, USA) according to the manufacturer's instructions. RNA concentrations were measured using a microplate spectrophotometer (Epoch; BioTek Instruments Inc., Winooski, VT, USA) at $260 \mathrm{~nm}$. RNA quality was evaluated by electrophoresis on $1 \%$ agarose gels. Total RNA $(1 \mu \mathrm{g})$ was reverse transcribed into first-strand complementary DNA (cDNA) using Moloney murine leukemia virus reverse transcriptase (Invitrogen Life Technologies) and random primers (9-mer; Takara Bio, Inc., Otsu, Shiga, Japan). Each cDNA sample $(1 \mu \mathrm{l})$ was amplified with $10 \mu \mathrm{l}$ of $2 \mathrm{X} \mathrm{SYBR}^{\circledR}$ Premix Ex Taq $^{\mathrm{TM}}$ (Takara Bio, Inc.) and 10 pmol of each primer. Amplification was performed using a 7300 Real-time PCR System (Applied Biosystems, Foster City, CA, USA) with the following parameters: Denaturation at $95^{\circ} \mathrm{C}$ for $5 \mathrm{~min}$ followed by 40 cycles of denaturation at $95^{\circ} \mathrm{C}$ for $30 \mathrm{sec}$, annealing at $60^{\circ} \mathrm{C}$ for $30 \mathrm{sec}$ and extension at $72^{\circ} \mathrm{C}$ for $45 \mathrm{sec}$. The following sequences of oligonucleotide primers were used in the present study: IL-1 $\beta$, sense 5'-GAAATGCCACCTTTTGACAGTG-3' and antisense 5'-CTGGATGCTCTCATCAGGACA-3'; IL-6, sense 5'-CTGCAAGAGACTTCCATCCAG-3' and antisense 5'-AGTGGTATAGACAGGTCTGTTGG-3'; $\beta$-actin, sense 5'-TTCTACAATGAGCTGCGTGTG-3' and antisense 5-ACCAGAGGCATACAGGGACA-3'. Relative expression levels in each sample (normalized to that of $\beta$-actin) were determined using RQ software (version 1.3; Applied Biosystems).

Statistical analysis. Data are presented as the mean \pm standard error of the mean and were analyzed by one-way analysis of variance followed by Tukey's multiple comparison test. Statistical analyses were performed using GraphPad Prism software (version 4.0; GraphPad Software Inc., La Jolla, CA, USA). $\mathrm{P}<0.05$ was considered to indicate a statistically significant difference.

\section{Results}

Effect of VOCCo on skin lesions and serum IgE levels in $D N C B$-treated mice. For investigation of the anti-allergic effects of VOCCo in an AD-like mouse model, skin lesions were induced in BALB/c mice using multiple topical applications of DNCB for 8 weeks (Fig. 1). Marked inhibition of AD-like skin lesions was observed in the VOCCo (P1, P2 and $\mathrm{P} 3$ ) exposure groups. Treatment with DNCB resulted in induction of serum IgE levels (up to 7-fold) compared with 
A

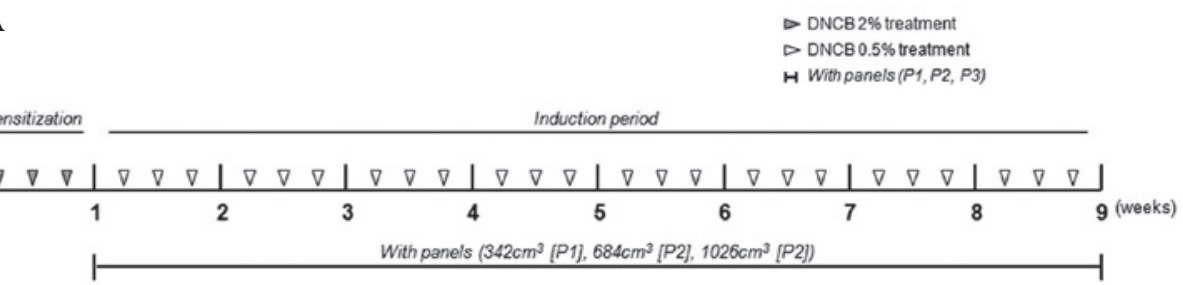

$\mathbf{B}$

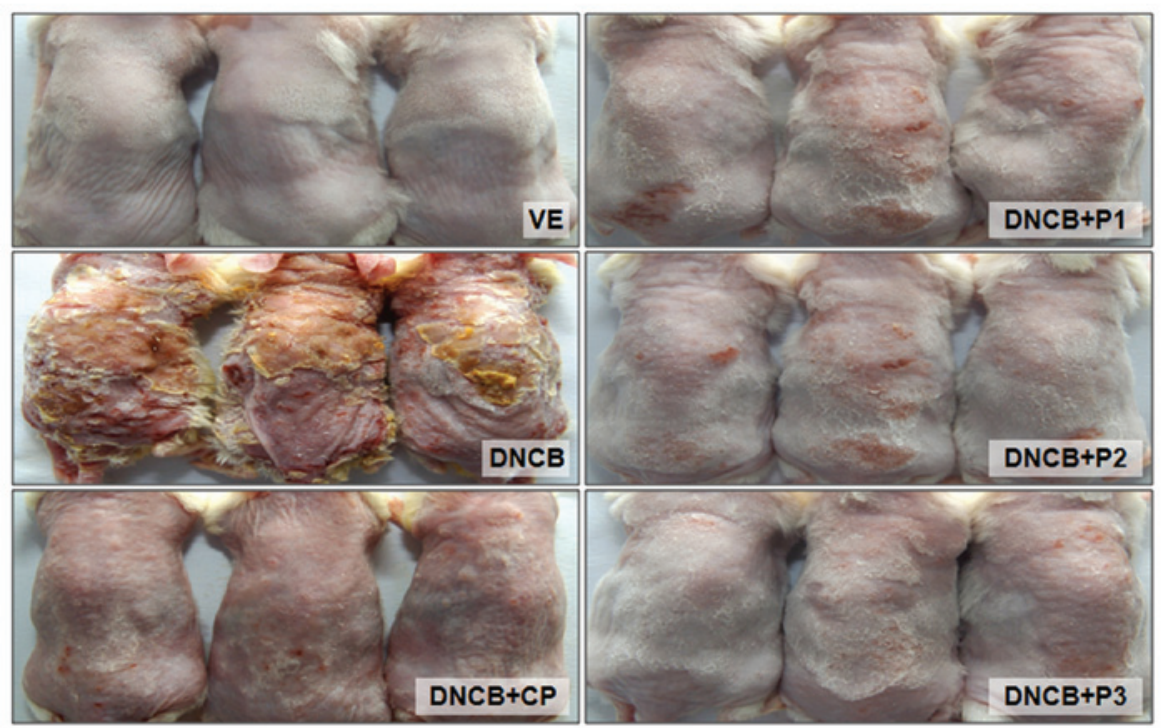

Figure 1. Schedule for DNCB-induced atopic dermatitis in BALB/c mice. (A) DNCB $(0.5 \%, 100 \mu 1)$ in acetone/olive oil (4:1) was applied to denuded sections of the dorsal skin of mice three times a week. CP was topically applied to the same area of mice three times a week. Mice were exposed to VOCCo $\left(\mathrm{P} 1: 362 \mathrm{~cm}^{3}\right.$, P2: $684 \mathrm{~cm}^{3}$ and P3: 1,026 $\mathrm{cm}^{3}$ ) for 8 weeks in polycarbonate cages. (B) Macroscopic observations of dorsal skin lesions in VOCCo-exposed BALB/c mice. DNCB, 2,4-dinitrochlorobenzene; CP, clobetasol propionate; VOCCo, volatile organic compounds of Chamaecyparis obtusa; VE, vehicle.

the VE group. The elevated serum IgE level was decreased by clobetasol propionate (CP) treatment (Fig. 2). Exposure to VOCCo (P1, P2 and P3) resulted in a significant decrease in the elevated IgE level and this anti-allergic effect on serum $\mathrm{IgE}$ level was the highest in the P3 exposure group. The results indicated that exposure to VOCCo can reduce IgE levels in the serum, suggesting that VOCCo can ameliorate the hyper-allergic reaction in an AD-like mouse model.

Histological findings in DNCB-treated mice. For observation of skin thickness and immune cell infiltration, DNCB-affected skin lesions were collected and stained with H\&E. As shown in Fig. 3, DNCB induced an increase in skin thickness in DNCB-treated mice, compared with the vehicle-treated group, and a decrease in VOCCo-exposed mice. VOCCo $\left(1,026 \mathrm{~cm}^{3}\right)$ was expected to have greater potential for recovery of AD-like skin compared with the therapeutic control, CP. To determine the distribution of mast cells beneath the dermis and hypodermis of AD-like mice, selected tissues were stained with toluidine blue staining solution following formalin fixation (Fig. 3A). The number of mast cells was counted under a light microscope (BX51; Olympus) and expressed as the number of cells per square millimeter of dorsal skin (Fig. 3A). Infiltration of mast cells in DNCB-treated mice increased upon treatment with DNCB only, while infiltration was significantly decreased upon exposure in all VOCCo exposure groups (Fig. 3B). These

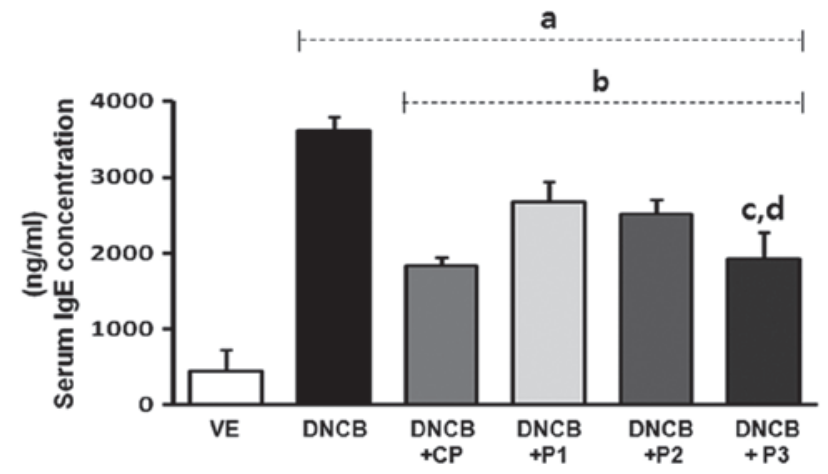

Figure 2. Effects of VOCCo on serum IgE levels in DNCB-induced mice. The serum IgE levels in BALB/c mice were measured at the end of the experiment (9 weeks later) using an ELISA kit. VE, vehicle; DNCB, negative control; $\mathrm{DNCB}+\mathrm{CP}$, positive control; $\mathrm{DNCB}+\mathrm{P} 1\left(342 \mathrm{~cm}^{3}\right), \mathrm{DNCB}+\mathrm{P} 2\left(684 \mathrm{~cm}^{3}\right)$ and $\mathrm{DNCB}+\mathrm{P} 3\left(1,026 \mathrm{~cm}^{3}\right)$ experimental groups. Values are expressed as the mean \pm standard deviation. ${ }^{\mathrm{a}} \mathrm{P}<0.05$ vs. $\mathrm{VE}$; ${ }^{\mathrm{b}} \mathrm{P}<0.05$ vs. DNCB-treated group; ${ }^{\mathrm{C}} \mathrm{P}<0.05$ vs. $\mathrm{DNCB}+\mathrm{P} 1 ;{ }^{\mathrm{d}} \mathrm{P}<0.05$ vs. $\mathrm{DNCB}+\mathrm{P} 2$. VOCCo, volatile organic compounds of Chamaecyparis obtusa; IgE, immunoglobulin E; DNCB, 2,4-dinitrochlorobenzene; $\mathrm{CP}$, clobetasol propionate.

findings suggest that VOCCo can inhibit the progression of AD-like skin lesions in the DNCB-induced AD mouse model.

Effect of VOCCo on the expression of proinflammatory cytokines in AD-induced mice. To determine the effect of VOCCo 
A
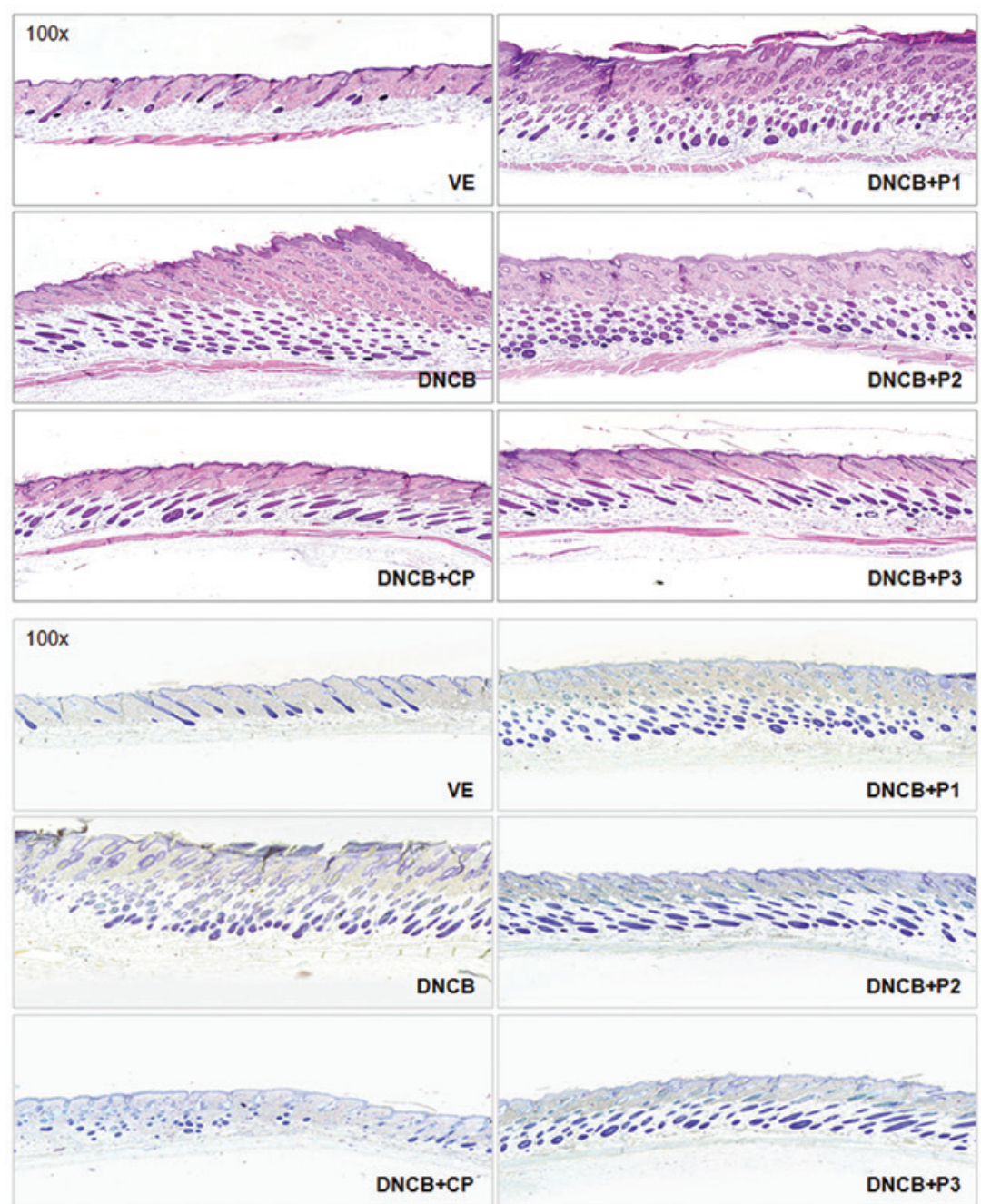

B

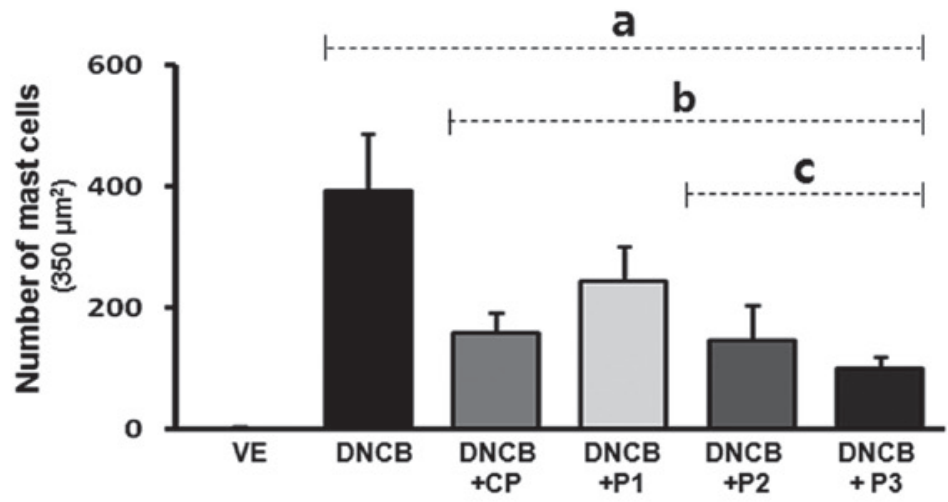

Figure 3. Effects of VOCCo on the histological dorsal skin lesions of DNCB-treated mice. Histological recovery of the dorsal skin lesion and mast cell infiltration beneath the dermis and hypodermis was observed in DNCB-treated and VOCCo-exposed mice. (A) Upper panel, hematoxylin and eosin stain; lower panel, toluidine blue stain. (B) Number of infiltrated mast cells was determined under a light microscope (magnification, x100) and expressed as the number of cells per $\mathrm{mm}^{2}$ of dorsal skin. Values are presented as the mean \pm standard deviation. ${ }^{\mathrm{a}} \mathrm{P}<0.05$ vs. VE; ${ }^{\mathrm{b}} \mathrm{P}<0.05 \mathrm{vs}$. DNCB-treated group; ${ }^{\mathrm{C}} \mathrm{P}<0.05$ vs. $\mathrm{DNCB}+\mathrm{P} 1$; ${ }^{d} \mathrm{P}<0.05$ vs. $\mathrm{DNCB}+\mathrm{P} 2$. VOCCo, volatile organic compounds of Chamaecyparis obtusa; DNCB, 2,4-dinitrochlorobenzene; CP, clobetasol propionate; VE, vehicle.

on the proinflammatory cytokines, IL-1 $\beta$ and IL-6, the transcriptional expression of these cytokines in DNCB-induced AD was evaluated. As shown in Fig. 4, the expression of IL-1 $\beta$ and IL-6 cytokines of the skin were induced by DNCB treatment. Elevated expression of dermal IL-1 $\beta$ and IL-6 mRNA was attenuated by $\mathrm{CP}$ treatment in $\mathrm{AD}$-induced mice. Expression of IL-6 mRNA demonstrated a decrease in all VOCCo groups (P1, P2 and P3) compared with the DNCB only treatment group. In addition, dermal IL-1 $\beta$ mRNA expression decreased. These results suggest that VOCCo can inhibit proinflammatory gene expression in the skin, which may be important in the suppression of allergic reactions in an AD mouse model. 

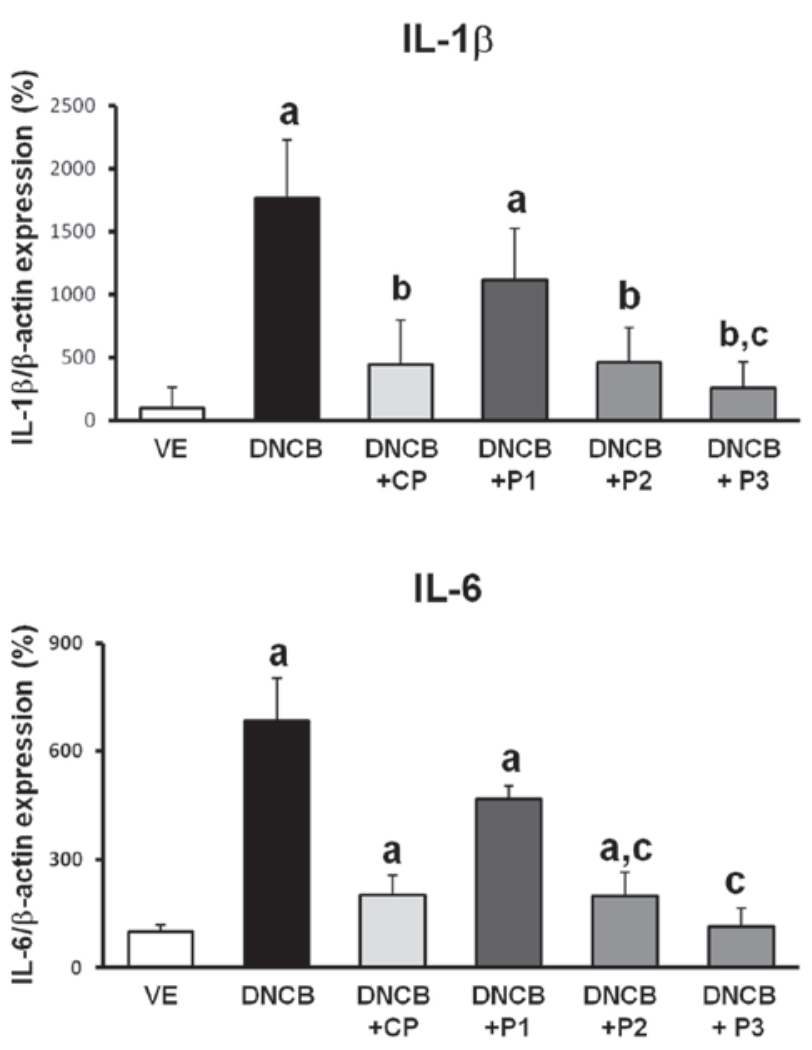

Figure 4. Proinflammatory cytokine mRNA expression in dorsal skin lesions of DNCB-treated mice. Isolated mRNA was analyzed by reverse transcription quantitative polymerase chain reaction for IL-1 $\beta$ and IL-6. Results were internally confirmed by the comparative CT method against $\beta$-actin as the standard gene. VE, vehicle; $\mathrm{DNCB}$, negative control; $\mathrm{DNCB}+\mathrm{CP}$, positive control; $\mathrm{DNCB}+\mathrm{P} 1, \mathrm{DNCB}+\mathrm{P} 2$ and $\mathrm{DNCB}+\mathrm{P} 3$ (2, 5 and $7 \%$ ), experimental groups. Values are presented as the mean \pm standard deviation. ${ }^{a} \mathrm{P}<0.05$ vs VE; ${ }^{b} \mathrm{P}<0.05$ vs. $\mathrm{DNCB}$-treated group; ${ }^{\mathrm{C}} \mathrm{P}<0.05$ vs. $\mathrm{DNCB}+\mathrm{P} 1 ;{ }^{\mathrm{d}} \mathrm{P}<0.05$ vs. $\mathrm{DNCB}+\mathrm{P} 2$. DNCB, 2,4-dinitrochlorobenzene; $\mathrm{CP}$, clobetasol propionate; VE, vehicle; IL, interleukin.

\section{Discussion}

Medications for AD comprise of oral or topical agents, including emollients, corticosteroids, calcineurin inhibitors and immunosuppressants (17). Numerous natural products are currently being investigated in order to determine whether they can be used for the treatment of AD (1). Corticosteroids may be used for the management of severe flares and rashes that cover a large part of the body $(17,18)$. Several corticosteroid ointments are also available for the control of AD-symptoms and are considered to have greater safety but a poorer efficacy compared with oral corticosteroids for the treatment of AD $(17,18)$. However, long term use of oral and topical corticosteroids is associated with a significant number of side effects and drug tolerance in the endocrine system of the body $(11,18)$. To avoid these side effects, certain medications are prescribed for a short course in an effort to calm the rash. Use of compounds from plants has previously been reported as an alternative method for anti-AD treatment and this type of treatment is expected to prevent the onset of allergic diseases and to ameliorate allergic symptoms $(19,20)$. The existence of Th1/Th2 subsets in Th lymphocytes provides a framework for understanding normal and pathological immune responses in allergic responses. Th1 and Th2 types of reactions can mutually regulate several immune signaling cascades. Therefore, balancing the Th1/Th2 types of reactions may be fundamental for the treatment of AD (21). Herbal therapy has become increasingly popular in Asia and Europe as a result of its successful use over extended time periods. A wide variety of phenolic substances derived from plants have been reported to retain marked antioxidant and anti-inflammatory activities, which contribute to their chemopreventive potential (22). In addition, the VOC of plants have been reported to exhibit different antioxidant activities, which may support or directly act as an effective antioxidant (23). In previous studies, C. obtusa oil has been demonstrated to possess antimicrobial and antifungal activities $(24,25)$ and its use has resulted in the improvement of the skin condition of eczematous lesions of AD caused by the mite antigen. A previous study reported that treatment with C. obtusa oil resulted in attenuation of the symptoms of AD in patients with dry scaly skin lesions by modulation of interferon- $\gamma$ and ILs (12).

The current study investigated the effects of VOCCo in a DNCB-induced AD mouse model. The induced serum IgE level was significantly decreased by application of VOCCo in DNCB-induced AD mice. In addition, this treatment resulted in the recovery of histological features. Exposure to VOCCo was demonstrated to result in successful elimination of the AD symptoms of skin lesions and mast cell infiltration beneath the hypodermis was also effectively inhibited. Cytokine mRNAs (IL-1 $\beta$ and IL-6) from skin lesions of DNCB-treated mice were significantly inhibited, suggesting that VOCCo may contribute to suppression of the stimulation of T cell-mediated cytokines in DNCB-induced mice.

Over the last half century, topical corticosteroids have been the primary choice for the treatment of AD. However, conditions, including skin atrophy, striae and perioral dermatitis, in sensitive areas (face or skin folds) have prevented the long-term use of corticosteroids for the treatment of AD (26). Previously, new topical calcineurin inhibitors, including tacrolimus ointment and pimecrolimus cream, have been used for monotherapy treatment of AD when conventional treatments, including corticosteroids are unsuccessful, however, the medicine was ineffective for the treatment of AD. Numerous patients stop seeking help from conventional physicians and turn to alternative medical approaches (27); these can include natural products. Although the mechanisms of herbal remedies have not yet been fully elucidated, a number of remedies may have scientific merit and clinical benefit for patients $(12,13,19,27,28)$.

In conclusion, the present study demonstrated the anti-allergic effects of VOCCo in an AD mouse model. Based on the results of the present study, it appears that VOCCo may be a potential therapeutic compound for the treatment of $\mathrm{AD}$, and control of the levels of serum IgE and T cell-derived cytokines, IL-1 $\beta$ and IL-6 in skin lesions of an AD mouse model.

\section{Acknowledgements}

This study was supported by the Korea Forest Research Institute (grant no. KFRI-2013-P1) and the National Research Foundation of Korea grant of Korean government (MEST) (grant no. 2013-010514). 


\section{References}

1. Abramovits W: Atopic dermatitis. J Am Acad Dermatol 53 (Suppl 1): S86-S93, 2005.

2. Leung DY, Boguniewicz M, Howell MD, Nomura I and Hamid QA: New insights into atopic dermatitis. J Clin Invest 113: 651-657, 2004.

3. Shimizu N, Dairiki K, Ogawa S and Kaneko T: Dietary whey protein hydrolysate suppresses development of atopic dermatitis-like skin lesions induced by mite antigen in $\mathrm{NC} / \mathrm{Nga}$ mice. Allergol Int 55: 185-189, 2006.

4. Kang JS,Lee K,Han SB, et al: Induction of atopic eczema/dermatitis syndrome-like skin lesions by repeated topical application of a crude extract of Dermatophagoides pteronyssinus in $\mathrm{NC} / \mathrm{Nga}$ mice. Int Immunopharmacol 6: 1616-1622, 2006.

5. Grabbe S and Schwarz T: Immunoregulatory mechanisms involved in elicitation of allergic contact hypersensitivity. Immunol Today 19: 37-44, 1998.

6. Bardana EJ Jr: Immunoglobulin E-(IgE) and non-IgE-mediated reactions in the pathogenesis of atopic eczema/dermatitis syndrome (AEDS). Allergy 78: 25-29, 2004.

7. Lee SO, Lou W, Nadiminty N, Lin X and Gao AC: Requirement for NF-(kappa)B in interleukin-4-induced androgen receptor activation in prostate cancer cells. Prostate 64: 160-167, 2005.

8. Georas SN, Guo J, De Fanis U and Casolaro V: T-helper cell type-2 regulation in allergic disease. Eur Respir J 26: 1119-1137, 2005.

9. Garrigue JL, Nicolas JF, Fraginals R, Benezra C, Bour H and Schmitt D: Optimization of the mouse ear swelling test for in vivo and in vitro studies of weak contact sensitizers. Contact Dermatitis 30: 231-237, 1994.

10. Gong JH, Shin D, Han SY, et al: Blockade of airway inflammation by kaempferol via disturbing Tyk-STAT signaling in airway epithelial cells and in asthmatic mice. Evid Based Complement Alternat Med 2013: 250725, 2013.

11. Dharmage SC, Lowe AJ, Matheson MC, Burgess JA, Allen KJ and Abramson MJ: Atopic dermatitis and the atopic march revisited. Allergy 69: 17-27, 2014.

12. Joo SS, Yoo YM, Ko SH, et al: Effects of essential oil from Chamaecypris obtusa on the development of atopic dermatitis-like skin lesions and the suppression of Th cytokines. J Dermatol Sci 60: 122-125, 2010.

13. Park D, Jeon JH, Kwon SC, et al: Antioxidative activities of white rose flower extract and pharmaceutical advantages of its hexane fraction via free radical scavenging effects. Biochem Cell Biol 87: 943-952, 2009.

14. Lehmann I, Rehwagen M, Diez U, et al: Enhanced in vivo IgE production and $\mathrm{T}$ cell polarization toward the type 2 phenotype in association with indoor exposure to VOC: results of the LARS study. Int J Hyg Environ Health 204: 211-221, 2001.
15. Diez U, Kroessner T, Rehwagen M, et al: Effects of indoor painting and smoking on airway symptoms in atopy risk children in the first year of life results of the LARS-study. Leipzig allergy high-risk children study. Int J Hyg Environ Health 203: 23-28, 2000.

16. Wieslander G, Norbäck D, Björnsson E, Janson C and Boman G: Asthma and the indoor environment: the significance of emission of formaldehyde and volatile organic compounds from newly painted indoor surfaces. Int Arch Occup Environ Health 69: 115-124, 1997.

17. Boguniewicz M and Leung DY: Atopic dermatitis: a disease of altered skin barrier and immune dysregulation. Immunol Rev 242: 233-246, 2011.

18. de Bruin-Weller MS and Bruijnzeel-Koomen CA: Topical immunomodulators, such as tacrolimus and pimecrolimus, in the treatment of atopic dermatitis. Ned Tijdschr Geneeskd 149: 1096-1100, 2005 (In Dutch).

19. Kawai M, Hirano T, Higa S, et al: Flavonoids and related compounds as anti-allergic substances. Allergol Int 56: 113-123, 2007.

20. Tan HY, Zhang AL, Chen D, Xue CC and Lenon GB: Chinese herbal medicine for atopic dermatitis: a systematic review. J Am Acad Dermatol 69: 295-304, 2013.

21. Heinzel FP, Sadick MD, Holaday BJ, Coffman RL and Locksley RM: Reciprocal expression of interferon gamma or interleukin 4 during the resolution or progression of murine leishmaniasis. Evidence for expansion of distinct helper $\mathrm{T}$ cell subsets. J Exp Med 169: 59-72, 1989.

22. Surh YJ, Na HK, Lee JY and Keum YS: Molecular mechanisms underlying anti-tumor promoting activities of heat-processed Panax ginseng CA Meyer. J Korean Med Sci 16: S38-S41, 2001.

23. Jang HW, Ka MH and Lee KG: Antioxidant activity and characterization of volatile extracts of Capsicum annuum L. and Allium spp. Flavour Fragr J 23: 178-184, 2008.

24. Hong EJ, Na KJ, Choi IG, Choi KC and Jeung EB: Antibacterial and antifungal effects of essential oils from coniferous trees. Biol Pharm Bull 27: 863-866, 2004.

25. Lee HO, Baek SH and Han DM: Antimicrobial effects of Chamaecypris obutusa essential oil. Korean J Appl Microbiol Biotechnol 29: 253-257, 2001.

26. Thaçi D: Long term management of childhood atopic dermatitis with calcineurin inhibitors. Hautarzt 54: 418-423, 2003 (In German).

27. Vender RB: Alternative treatments for atopic dermatitis: a selected review. Skin Therapy Lett 7: 1-5, 2002.

28. Wang W, Zhou Q, Liu L and Zou K: Anti-allergic activity of emodin on IgE-mediated activation in RBL-2H3 cells. Pharmacol Rep 64: 1216-1222, 2012. 